\title{
GASTROINTESTINAL NON-HODGKIN'S LYMPHOMA CLINICO-PATHOLOGIC STUDY
}

\author{
By \\ Fatin M. Al-Sayes, MSc, MRCPath
}

\author{
From \\ Assistant Professor/Consultant Haematologist \\ Department of Haematology King Abdulaziz \\ University Hospital Jeddah, Saudi Arabia
}

\begin{abstract}
Objectives:

The aim of this study is to determine the clinicopathologic features of primary gastrointestinal nonHodgkin's lymphoma (GI NHL) at King Abdulaziz University HospitalJeddah, and to compare our results to those reported in the literatures.
\end{abstract}

\section{Patients and Methods :}

Twenty three adult patients with primary GI NHL diagnosed over 5years period (2000-2005) were retrospectively studied clinically and histo-. pathologically. They were classified using the REALWHO histopathologic classification.

Results :

Of the 23 patients with primary GI
NHL, 14 (60.9\%) were Saudi, with male to female ratio of $1.3: 1$. The mean age of the male patients was 61. 3 years ranging from (42-83) years with a $S D \pm 13.09$ while for females was 64 years, age range (5075) with a $S D \pm 9.14$.Abdominal pain was the most common presenting symptoms $(78.3 \%)$ and the most common primary site was the stomach $(73.9 \%)$ followed by the small bowel $(13 \%)$. The most frequent histologic subtype was the diffuse largeB cell lymphoma accounting for $(60.9 \%)$ of all cases, followed by marginal-zone cell lymphoma (MALT type) which was Helicobacter pylori associated in (39.1\%). A large proportion of patients with primary GI NHL had early disease (Stage IE: $20 \%$, Stage IIE 58.6\%). In regards to treatMANSOURA MEDICAL JOURNAL 
ment 15 patients $(65.2 \%)$ had chemotherapy, while only 2 patients $(8.7 \%)$ were treated by Helicobacter pylori eradication. The overall 5 years survival was $(47.8 \%)$.

\section{Conclusion :}

The data demonstrated that primary GI NHL is more common among males, mainly in their sixth decade. Abdominal pain is the most common diagnostic symptoms, with stomach being the most common involved site. Diffuse large-B cell lymphoma is the most frequent histologic subtype, followed by extra-nodal marginal zone B-cell lymphoma (MALT type), Helicobacter associated. The majority of the cases have early disease (Stage IE and IIE) and mostly treated by combination chemotherapy.

Keyword : Primary GI NHL, Epidemiology, Histopathology.

\section{INTRODUCTION}

The gastrointestinal (Gl) tract is the predominant site of extranodal non-Hodgkin's lymphoma (NHL) (1). It is accounted for about $1 / 3$ of all primary extranodal $\mathrm{NHL}$ (2), but only 1 Vol. 37, No. 1 \& 2 Jan., \& April, 2006 to $4 \%$ of malignancies arising in the GI (3).

The rarity of primary GI NHL $(0.8$ to 1.2 cases per 100,000 persons per year) lends itself to mainly retrospective studies reporting only small patient numbers or to studies that have been conducted over periods of up to two decades or more (2). Despite their rarity, primary $\mathrm{NHL}$ of the GI tract are important, since their epidemiologic features, staging, histologic classification and management are distinct from that of primary extranodal lymphoma (4). Primary GI NHL can be operationally defined as lymphoma in which the main bulk of the disease is confined to the GI tract, necessitating treatment directed towards that site (5). The mucosaassociated lymphoid tissue (MALT) published by Isaacson et al (6), revolutionized our concept of the pathogenesis of primary GI NHL and suggested that lymph node-based classification system may not be fully applicable. MALT lymphoma tend to occur in order of frequency in the stomach, small bowel, ileocecal area, colon and the esophagus (7). 
Epidemiologic studies support a strong association between MALT type NHL and Chronic Helicobacter pylori infection (8). The most dramatic evidence supporting a pathogenetic role for $\mathrm{H}$. pylori in MALT type NHL is remission of the tumor following eradication of $\mathrm{H}$. pylori with antibiotic therapy (9).

The aim of the current study is to analyse the clinicopathologic features of primary GI NHL at King Abdulaziz University Hospital (KAUH), Jeddah. Our results will be compared to those reported in the literatures.

\section{MATERIALS AND METHODS}

Patient population :

A total of 23 cases of adult patients with primary GI NHL diagnosed at KAUH during (2000-2005) were studied retrospectively. Medical records of all patients were reviewed, clinical and pathological informations were recorded in a structured questionnaire form. Primary GI NHL were defined according to Lewin et al (5). The laboratory and radiological workup included complete blood count, creatinine, liver enzymes, lactate dehydrogenase normal range $(200-450$
IU/L), uric acid, chest X-ray, computed tomography of chest and abdomen, bone marrow biopsy and endoscopic evaluation with multiple biopsies of the upper and lower GI tract.

Histology and Immunohistochemistry:

Tissue sections were obtained from formalin-fixed paraffin blocks and stained with hematoxylin and eosin. Special stain such as Periodic Acid-Schiff (PAS) and reticulin stain were used in selected cases whenever indicated. Each biopsy was investigated immunohistochemically by staining for Leucocyte Common Antigen (LCA), CD20, CD79, CD3 and CD45. Additionally, Helicobacter pylori was demonstrated using either fast cresyl violet or Giemsa stain.

Clinical Staging and Histopathologic Classification :

Patients were staged according to the Ann Arbor Classification in its modification by Musshoff (10). Histopathologic classification was done using the current REALWHO classification (11).

MANSOURA MEDICAL JOURNAL 
Statistical analysis was done using SPSS version 10 .

\section{RESULTS}

From 2000 through 2005, 23 patients with primary GI NHL were accrued to the study, $14(60.9 \%)$ were Saudi and $9(39.1 \%)$ were non-Saudi. Thirteen patients were males $(56.5 \%)$ while 10 were females $(43.5 \%)$. The male to female ratio was $1.3: 1$. The mean age for males was 61.3 years ranging from $(42-83)$ years with a SD \pm 13.09 and for females was 64 years, age range (50-75) with a SD \pm 9.14 .

Abdominal pain was the most common diagnostic symptom (78.3\%), followed by abdominal mass (21.7\%). The most common primary site was the stomach $(73.9 \%)$, followed by the small bowel (13\%). The third largest group was lymphoma originating in the colon $(8.7 \%)$ followed by those of the mesentery (4.4\%).

Characteristic features of patients with primary $\mathrm{GI} \mathrm{NHL}$ are summarized in (Table 1.)

B symptoms occurred in (60.9\%) of the cases. Median time from onset of symptoms to diagnosis was 180 days. Lactate dehydrogenase level, which is an important prognostic factor at least in high grade $\mathrm{NHL}$, was elevated in approximately (17.4\%) of all patients. Normocytic normochromic anemia was seen in $(56.5 \%)$. Other laboratory tests including white blood cell, platelets count, uric acid level, creatinine and liver enzymes were normal; majority of these patients had also positive B symptoms $(72.7 \%)$. The most frequent histologic subtype was the diffuse large B-cell lymphoma accounting for $(60.9 \%)$ of all cases, followed by MALT type lymphoma $(39.1 \%)$ which corresponds to the marginal-zone cell lymphoma in the REALNHO classification.

All marginal-zone cell lymphoma (MALT type) were of gastric origin. In $2(8.7 \%)$ cases of the diffuse large-B cell lymphoma, a simultaneous low grade MALT type component count is demonstrated. Helicobacter pylori bacilli ( $H$. pylori) could be identified on histologic sections in all the 9 cases $(39.1 \%)$; the serologic test for $\mathrm{H}$. pylori was available only for 5 cases which was positive. Gl endoscopy 
revealed that mass or filling defect was seen in $80 \%$ of cases, followed by ulcerated lesions and diffuse thickening of the mucosa in $(15 \%),(5 \%)$ respectively. According to a modified staging classification, a larger proportion of patients with Gl lymphoma had early disease (Stage IE: 20\%, Stage IIE $58.6 \%$ ) while stage IIIE and IVE accounted for $4 \%, 17.4 \%$ respectively.

In regards to treatment, 5 (21.7\%) had gastrectomy followed by chemo- therapy, $1(4.3 \%)$ received multimodality treatment in the form of gastrectomy and chemotherapy followed by radiotherapy. Fifteen patients $(65.2 \%)$ had chemotherapy only and the remaining patients two $(8.7 \%)$ were treated with Helicobacter pylori eradication. The mean follow-up for all cases was 42.2 months. The overall 5 years survival was $(47.8 \%)$, outcome in patients with primary GI NHL in relation to histology is shown in Table 2. 
Table 1. Characteristic ieatures of patients with primary GI NHL.

\begin{tabular}{|l|c|c|}
\hline \multicolumn{1}{|c|}{ Characteristic } & No. & $\%$ \\
\hline Age: & & \\
$\geq 50$ & 19 & 82.6 \\
$\leq 50$ & 4 & 17.4 \\
\hline Sex: & 13 & \\
Males & 10 & 56.5 \\
Females & & 43.5 \\
\hline Race: & 14 & 60.9 \\
Saudi & 9 & 39.1 \\
Non-Saudi & 5 & 21.7 \\
\hline +ve Lymphadenopathy & 18 & 78.3 \\
-ve Lymphadenopathy & 18 & 78.3 \\
\hline +ve Abdominal pain & 5 & 21.7 \\
-ve Abdominal pain & 14 & 60.9 \\
\hline +ve B symptoms (fever, & & \\
$\quad$ night sweat, weight loss) & 9 & 39.1 \\
-ve B symptoms & 1 & 4.3 \\
\hline +ve Bone marrow & 22 & 95.7 \\
involvement \\
-ve Bone \\
involvement
\end{tabular}

Table 2. Outcome of primary GI NHL in relation to different histology.

\begin{tabular}{|l|c|c|c|c|}
\hline \multirow{2}{*}{} & \multicolumn{2}{|c|}{$\begin{array}{c}\text { Marginal Zone } \\
\text { Lymphoma } \\
\text { (MALT type) }\end{array}$} & \multicolumn{2}{c|}{$\begin{array}{c}\text { Diffuse Large B-cell } \\
\text { Lymphoma }\end{array}$} \\
\cline { 2 - 5 } & $\begin{array}{c}\text { No. of } \\
\text { patients }\end{array}$ & $\%$ & $\begin{array}{c}\text { No. of } \\
\text { patients }\end{array}$ & $\%$ \\
\hline Cured & 6 & 26 & 5 & 21.7 \\
\hline Remission & 2 & 8.7 & 2 & 8.7 \\
\hline Relapse & 1 & 4.3 & 2 & 8.7 \\
\hline Died & - & - & 2 & 8.7 \\
\hline Lost to follow-up & - & - & 3 & 13 \\
\hline
\end{tabular}

Vol. 37, No. 1 \& 2 Jan., \& April, 2006 


\section{DISCUSSION}

NHL constituted a group of disorders originating from the malignant transformation of lymphocytes and involving either the lymph nodes or extranodal sites. Extranodal lymphomas may comprise $24 \%-48 \%$ of NHL cases and that appears to be an increasing incidence of these lymphoma during the past decades (12). Primary GI $\mathrm{NHL}$ is a heterogenous disease with regards to patient's characteristics, stage, histologic subtypes, and treatment results (13). King Abdulaziz University Hospital in Jeddah is considered as a referral center in the Western part of Saudi Arabia with admission facilities for non-Saudi patients. The results from the current study indicate that percentage of nonSaudi patients was $(43.5 \%)$. Males were more than females with male to female ratio of $1.3: 1$. This figure is lower than what has been reported from Jordan (14) and the West (2), but is close to the ratio reported from Thailand (15) and China (16).

The peak age of our patients was in the sixth decade, which is older than the age group of a previous study from the Kingdom of Saudi Arabia (17). The GI NHL diagnosis is rarely suspected because of the non- specific presenting symptoms and signs (18). Abdominal pain tends to be the predominant symptom, occurring in up to $93 \%$ of patients (19). In our patients with GI NHL abdominal pain was the most common diagnostic symptoms at presentation, followed by abdominal mass in $(78.3 \%)$ and $(21.7 \%)$ respectively. The high incidence of gastrointestinal bleeding seen in GI NHL was not a manifesting complaints in our patients population(16) .

Primary gastric lymphoma accounts for $3 \%$ of gastric neoplasms and $10 \%$ of lymphomas. The stomach is the most common extranodal site of lymphoma and is also the most common site of GI NHL (19). Gastric lymphoma can arise from mucosal areas, the so called Marginal zone lymphoma of MALT type. Diffuse large Bcell lymphoma may also arise within the stomach as a primary lesion (previously called "high grade" MALT lymphoma (20). In our patients sites of involvement were the stomach $(73.9 \%)$, small bowel (13\%), colon $(8.7 \%)$ followed by those in the mesentery in $(4.4 \%)$. These results were similar to a previous results from KSA (17), Bahrain (21), United Arab Emirates (22), Jordan (14), Thailand (15), China

MANSOURA MEDICAL JOURNAL 
(16), Japan (23) and the West (2).

The situation is likely to be quite different in Mediterranean countries with the problem of immunoproliferative small intestinal disease is common (24). The duration of symptoms is often long (19), in our series, median time from onset of symptoms to diagnosis was 180 days. This delay in presentation is because the diagnosis is rarely suspected, due to the nonspecific symptoms of GI NHL. Diffuse large B-cell lymphoma is the commonest histologic subtype of GI NHL in most of the series $(14-17,19,25)$. It involves MALT sites. It is characterized by the presence of blast cell in excess of $20 \%$ or more. These patients tend to have more systemic symptoms and advanced stage at diagnosis. In the current study $(60.9 \%)$ of patients with diffuse large B-cell lymphoma, interestingly B-symptoms occurred in $(60.9 \%)$ of the cases, $(56.5 \%)$ of them were among the diffuse large B-cell lymphoma. Extranodal marginal zone B-cell lymphoma (MALT type) has linked to clonal expansion of $B$ cells that accompanies chronic gastritis in the presence of Helicobacter pylori infection. It accounts for about $40-50 \%$ of GI NHL (25). In our study, Marginal zone Bcell lymphoma (MALT type) was
$(39.1 \%)$ of all cases, all of them were Helicobacter pylori positive on the histologic section. These findings are similar to a previous studies $(14,21,26)$. All the GI NHL in this study were of B-cell origin, one explanation for the high frequency of B-cell lymphoma might be the fact that B-cell undergo clonal expansion during proliferation in the microenvironment of the germinal center. It appears that Bcell lymphoma often need stimulation that involves the antigen receptor or other receptors on the surface of the lymphoma cells. It could be that the stimulus is the same in the different sites of origin of B-cell lymphoma (27). Upper and lower gastrointestinal endoscopy is very useful in the diagnosis of GI NHL. Our cases showed masses or filling defects in $80 \%$ of the cases followed by ulcerated lesions $(15 \%)$ and diffuse thickening of the mucosa (5\%). At presentation $(78.6 \%)$ of our patients had stage IE and IIE. Two authors reported $87 \%$ $(28,19)$ and $89 \%$ which is comparable to our data.

Treatment strategies in GI NHL are debatable, particularly in gastric lymphoma. Surgery, radiotherapy and chemotherapy have been used alone or in various combinations (25). The 
association of Marginal zone B-cell lymphoma (MALT type) with H. pylori has been dramatically demonstrated by regression of gastric MALT lymphoma following treatment aimed at eradicating $\mathrm{H}$. pylori (8). Complete histologic regression has been demonstrated in 50 to $80 \%$ of carefully selected patients. For instance in patients with localized stage (IE) mucosal disease are candidates for anti-H. pylori therapy. It is estimated that less than $10 \%$ of patients with gastric lymphoma are in this catego$\mathrm{ry}$, as the majority have aggressive histology (ie, diffuse large B-cell lymphoma), extensive mural involvement, or advanced stage (Stage IIE to IV))29). In the current study ( $8.7 \%$ ) only were treated by Helicobacter pylori eradication, the two patients were early stage (IE), remission was achieved and they are still under observation. Combination chemotherapy is usually reserved for patients failing or recurring after other less aggressive therapies, those with advanced stage disease (i.e. Stages $\mathrm{IIE}-\mathrm{VI}$ ) and those with diffuse large Bcell lymphoma (17). The original concern that chemotherapy in a patient with involvement of the stomach might lead to gastric perforation and/ or bleeding has not been confirmed in a number of comparative studies $(30,31)$. In this series $(21.7 \%)$ had gastrectomy before chemotherapy, and $(4.3 \%)$ received radiotherapy in addition to surgery and chemotherapy. Majority of our patients $(65.2 \%)$ were treated by chemotherapy (Anthracyclin containing regimen). Since our study is retrospective, and the numbers of patients are small, conclusion about treatment efficacy should be made with caution.

\section{In Conclusion :}

The current study showed that primary $\mathrm{Gl}: \mathrm{VHL}$ is commoner among males than females, the peak age is in the sixth decade. Abdominal pain is the most common presenting symptoms with not surprising delay in diagnosis, because of the very nonspecific complaints. Gastric NHL accounted for the majority. Diffuse large B-cell lymphoma represents the most common histologic subtype while the extra-nodal marginal zone B-cell lymphoma (MALT type), Helicobacter pylori associated is the next. At presentation $78.6 \%$ of the cases had early stages. Anthracyclin containing regimen is the frequently used treatment modality.

MANSOURA MEDICAL JOURNAL 


\section{Future Study :}

The data presented here is an approximate assessment of the epidemiological features of primary GI NHL. Further studies together with national cancer registry data will probably make attempts to identify epidemiology and risk factors for primary GI NHL which is needed to make definite preventive and therapeutic measures. Moreover, it will be interesting to define the molecular background of this group of malignancy among our patients.

\section{REFERENCES}

1. Paryani S, Hoppe R, Burke J. (1983) : Extralymphatic involvement in diffuse nonHodgkin's lymphoma. J Clin Oncol;1:682-688.

2. Ducreux M, Boutron M, Piard F, Caril P, Faivre J. (1998) : A 15 year series of gastrointestinal non-Hodgkin's lymphoma: A population-based study. British Journal of Cancer.; 77(3):511-514.

3. Loehr W, Mujahed Z, Zahn F. (1969) : Primary lymphoma Vol. 37, No. 1 \& 2 Jan., \& April, 2006 of the gastrointestinal tract: A review of 100 cases. Ann Surg; 170:232.

4. Herrmann R, Panahon A, Barcos M. (1980) : Gastrointestinal involvement in nonHodgkin's lymphoma. Cancer; 46:215-222.

5. Lewin K, Ranchod M, Dorfman R. (1978) : Lymphoma of the gastrointestinal tract: $A$ study of 117 cases presenting with gastrointestinal disease. Cancer; 42:693-707.

6. Isaacson P, Wright D. (1984) : Extranoda I malignant lymphoma arising from mucosa-associated lymphoid tissue. Cancer; 53 : 2515-2524.

7. Koh P, Horsman J, Radstone C, Hancock H, Goepel J, Hancock B. (2001) : Localized extranodal nonHodgkin's lymphoma of the gastrointestinal tract: Sheffield lymphoma group experience (1989-1998). Int J 
OncoL;18(4):743-748.

8. Muller A, lhorst G, Mertelsmann R, Engelhardt M. (2005) : Epidemiology of nonHodgkin's lymphoma (NHL): trends, geographic distribution, and etiology. Ann HematoL; 84(1):1-12.

9. Chiang I, Wang H, Cheng A, Lin J, Su I. (1996) : Low-grade gastric B-cell lymphoma of mucosa-associated lymphoid tissue: Clinicopathologic analysis of 19 cases. $\mathrm{J}$ Formos Med Assoc; 95 (11):857-865.

10. Musshoff K (1977) : Klinische stadieneinteilung der NichtHodgkin lymphoma. StrahLentherapie 1977;153:218221. Cited in Clinical Staging Classification of NonHodgkin's Lymphoma (Author's Transl) Strahlentheropie- Apr;53(4):218-21 German.

11. Harris N, Jaffe E, Stein $H$, et al: (1994) : A revised Europe- an American classification of lymphoid neoplasms: A proposal from the international lymphoma study group. Blood;(84):13611392.

12. d'Amore F, Christensen BE, Brincker H. (1991) : Clinicopathologic features and prognostic factors in extranodal non-Hodgkin lymphomas. Danish LYFO Study Group. Eur J Cancer; 27:1201-1208.

13. Eser B, Kaplan B, Unal A, Canoz O, Altuntas F, Sari HI, Er O, Ozkan M, Kucuk C, Arar M, Gursoy S, Cetin M. (2006) : Clinicopathologic characteristics and therapeutic outcome of primary gastrointestinal nonHodgkin's lymhomas in central Anatolia, in Turkey. Yonsei Med J.Feb 28;47 (1):22-33.

14. Bani-Hani K, Yaghan R, Matalka I. (2005) : Primary gastric lymphoma in Jordan with MANSOURA MEDICAL JOURNAL 
special emphasis on descriptive epidemiology. Leuk Lymphoma Sep; 46(9) : 1337-1343.

15. Sukpanichnant $S$, UdomsakdiAuewarakul C, Ruchutrakool T, Leelakusolvong S, Boonpongmanee S, Chinswangwatanakul V. (2004) : Gastrointestinal lymphoma in Thailand: A clinicopathologic analysis of 120 cases at Siriraj hospital according to WHO classification. Southeast Asian J Trop Med Public Health Dec;35 (4):966-976.

16. Liang R, Todd D, Chan TK, Ng RP, Ho FC. (1987) : Gastrointestinal lymphoma in Chinese: A retrospective analysis. HematoL Oncol Apr-Jun; 5(2):115-126.

17. Ibrahim E, Ezzat A, Raja M, Rahal M, Ajarim D, Mann B, Baloush A, Stuart R, Bzarbashi S. (1999) : Primary gastric non-Hodgkin's lymphoma: Clinical features, management, and prognosis of 185 patients with diffuse large B-cell lymphoma. Ann Oncol Dec;10 (12):1405-1407.

18. Bierman PJ. (2003) : Gastrointestinal lymphoma. Curr Treat Options Oncol. Oct; 4(5):421-430.

19. Koch P, Delvalle F, Berdel W. (2001) : Primary gastrointestinal non-Hodgkin's lymphoma anatomic and histologic distribution, clinical features and survival data of $\mathbf{3 7 1}$ patients registered in the german multicenter study GIT non-Hodgkin's lymphoma 01/92. J Clin OnCOL;19:3861-3873.

20. Schroy $P$, Freedman A. (2006) : Classification and pathology of gastrointestinal lymphomas. Up-to-date; 13. 3:1-10.

21. Shome DK, George SM, Al-Hilli F, Satir AA. (2004) : Spectrum of malignant lympho$\mathrm{ma}$ in Bahrain. Leitmotif of a 
regional pattern. Saudi Med J; vol 25(2):164-167.

22. Castella A, Joshi S, Raaschou T, Mason N. (2001) : Pattern of malignant lymphoma in the United Arab Emirates -A histopathologic and immunologic study in 208 native patients. Acta Oncologica; 40(5):660-664.

23. Nakamuras $S$, Matsumoto $T$, lida M, Yao T, Tsuneyoshi M. (2003) : Primary gastrointestinal lymphoma in Japan: A clinicopathologic analysis of 455 patients with special reference to its time trends. Cancer May 15;97(10):2462-2473.

24. Al-Saleem T, Al-Mondhiry $\mathrm{H}$. (2005) : Immunoproliferative small intestinal disease (IPSID): A model for mature B-cell neoplasms. Blood Mar 15;105(6):2274-2280.

25. Isaacson PG. (1999) : Mucosaassociated lymphoid tissue lymphoma. Semin HematoL Apr;36(2):139-147.
26. Cheng H, Wang J, Zhang CS, Yan PS, Zhang XH, Hu PZ, Ma FC. (2003) : Clinicopathologic study of mucosaassociated lymphoid tissue lymphoma in gastroscopic biopsy. World J Gastroenterol June;9(6):1270-1272.

27. Economopoulos T, Papagcorgiou S, Rontogianni d, Kaloutsi V, Fountzilas G, Tsatalas C, Pavlidis N, Pectasides D, Papageorgious $\mathbf{E}$, Dimopoulos M. (2005) : Multifocal extranodal non-Hodgkin's lyumphoma: A clinicopathologic study of 37 cases in Greece a Hellenic Cooperative Oncology group study. The Oncologist; 10:734-738.

28. Azab MB, Henny Amar M, Rougier P, et al. (1989) : Prognostic factors in primary gastrointestinal nonHodgkin's lymphoma: A multivariate analysis, report of 106 cases, and review of the literature. Cancer; 64:1208-1217. 
29. Zeid MA, Elbedewy AF, Awad I. (2005) : Primary gastric lymphoma: A clinicopathologic study. Hepatogastroenterology Mar-Apr; 52 (62):649-653.

30. Schmidt W, Schmitz N, Sonnen R. (2004) : Conservative management of gastric lymphoma: The treatment op- tion of choice. Leuk Lymphoma; 45:1847-1852.

31. Ferreri A, Cordio S, Ponzoni M, Villa E. (1999) : Nonsurgical treatment with primary chemotherapy with or without radiation therapy of stage I-II high-grade gastric lymphoma. Leuk Lymphoma; 33:531-541. 